\title{
Assistência ao Parto na Maternidade: Representações Sociais de Mulheres Assistidas e Profissionais de Saúde
}

\author{
Hospital Care at Childbirth: Social Representations of Women \\ and Health Care Professionals
}

\author{
Sandra Cristina da Silveira*, Brígido Vizeu Camargo \& Maria Aparecida Crepaldi \\ Universidade Federal de Santa Catarina
}

\begin{abstract}
Resumo
Estudo de caráter comparativo que teve por objetivo investigar representações sociais (RS) de mulheres assistidas (20) e profissionais de saúde (20), sobre a assistência ao parto em maternidades. Foram realizadas 40 entrevistas que examinaram duas maternidades com enfoques diferentes de assistência ao parto. Para a análise dos dados utilizou-se a análise lexicográfica e classificação hierárquica descendente dos textos (ALCESTE). Entre os profissionais encontraram-se duas representações distintas: a primeira, denota uma visão medicalizada da assistência, e a outra aponta para uma assistência identificada com a proposta do Movimento pela Humanização do Parto e Nascimento. Entre as mulheres assistidas a qualidade da relação estabelecida com os profissionais é o fator que maior influência parece exercer sobre a maneira como representam a assistência recebida.

Palavras-chave: Assistência ao parto; Humanização do parto; Representações sociais.

Abstract

The aim of this comparative study was to investigate social representations of assisted women (20) and health care professionals (20) concerning childbirth assistance in maternities. Forty interviews were made examining two maternities with different approaches to childbirth assistance. In dealing with the data, we used lexicographical analysis and hierarchical descending clustering of texts (ALCESTE software). Among the health care professionals, two distinct representations were found: the first denoting a medicalized vision of assistance, and the second pointing towards an assistance identified with the Humanization of Birth Movement. Among the assisted women, the quality of their relationship with health care professionals seems to be the main influence on the way they represent the received assistance. Keywords: Childbirth care; Humanizing childbirth; Social representations.
\end{abstract}

A qualidade da assistência prestada ao parto tem sido tema de preocupação em muitos países nos últimos 30 anos. O Dossiê mortalidade materna (Rede Feminista de Saúde, 2001) apresenta uma estimativa segundo a qual 515 mil mulheres morrem por ano no mundo por complicações relacionadas à gravidez, ao aborto, parto e puerpério, sendo que $99 \%$ dessas mortes ocorrem em países em desenvolvimento.

No Brasil, um estudo (Laurenti, Jorge, \& Gotlieb, 2004), revelou que, de 7.332 mortes de mulheres com idade entre 10 e 49 anos ocorridas no primeiro semestre de 2002 nas capitais brasileiras, 239 representavam óbitos por causas maternas, o que significa uma razão de mortalidade materna de 54,3 para 100.000 nascidos vivos no conjunto dessas cidades. Destas, 67,1\% corresponderam a mortes obstétricas diretas.

\footnotetext{
* Endereço para correspondência: Universidade Federal de Santa Catarina, Campus Reitor João David Ferreira Lima, Bairro Trindade, Florianópolis, SC, Brasil, CEP 88040-970. E-mail: sandradasilveira@hotmail.com
}

Dentre os partos ocorridos em 2004 nos hospitais brasileiros, 42,72\% foram cesáreos (Ministério da Saúde, 2006). É importante considerar que o nível máximo tecnicamente recomendado pela Organização Mundial da Saúde ([OMS], 1985) é de $15 \%$. Além disso, na realidade brasileira, situações de desrespeito e violência para com a mulher durante a assistência têm sido um tema recorrente nos resultados dos estudos aqui realizados (Alves, 2002; Caron \& Silva, 2002; Domingues, Santos, \& Leal, 2004; Fernandes, 2000; Hotimsky, Rattner, Venancio, Bógus, \& Miranda 2002), o que vem a reforçar a necessidade urgente de repensar a forma de tratamento das parturientes.

$\mathrm{Na}$ atualidade, o modelo hegemônico de assistência ao parto se caracteriza mais acentuadamente por utilizar uma abordagem intervencionista (Davis-Floyd \& St. John, 2004; Santos, 2002; Spink, 2003). Davis-Floyd e St. John (2004) compreendem essa abordagem como um reflexo do pensamento que norteia a medicina moderna, o qual as autoras denominam de "paradigma tecnocrático". Dentro dessa concepção, é o obstetra quem "faz" 
o parto, conforme assinala Santos (2002), destacando ainda o seguinte:

o modelo tecnocrático nos mostra a gravidez, parto e nascimento na perspectiva da sociedade industrializada, tecnológica, e sob a ótica masculina. A parturiente, assim, é vista enquanto um objeto sobre o qual alguns procedimentos e rotinas deverão ser realizados em todos os partos. (p. 113).

Embora a atual forma de assistência em muitos países seja ainda fortemente orientada pelo modelo de atendimento hospitalar/medicalizado, cresce nas últimas três décadas um movimento internacional que propõe modificá-la. Esse movimento tem como base consensual as propostas da OMS difundidas a partir de 1985 . No Brasil, é chamado de Movimento pela Humanização do Parto e Nascimento (MHPN).

O MHPN surgiu diante de evidências de que o uso irracional de tecnologia vem causando mais danos à mulher e ao bebê do que benefícios e tem uma preocupação que abrange, além de aspectos relativos à saúde pública, como a redução da taxa de cesáreas e mortalidade materna, também o bem-estar da mulher e do bebê. Defende-se a participação da parturiente nas decisões sobre sua saúde, a melhoria na relação profissional de saúde-paciente, a inclusão do pai no parto, a presença de doulas (mulheres que acompanham outras mulheres durante o trabalho de parto), e alguma negociação nos procedimentos de rotina. Porém, conforme analisa Diniz (2001), no Brasil, essas e outras recomendações vêm sendo desconsideradas, quando muito são conhecidas.

Desta forma, verifica-se a necessidade de promover mudanças na forma de atenção ao parto. Este estudo assumiu como pressuposto a idéia de que para mudar a assistência é importante identificar que concepção os sujeitos envolvidos têm sobre ela. Nesse sentido, recorreu-se à teoria das representações sociais, que se ocupa em estudar o conhecimento que o leigo utiliza para interpretar e compreender sua realidade social (Moscovici, 1978).

De acordo com Jodelet (2001), Representações Sociais (RS) são "uma forma de conhecimento, socialmente elaborada e partilhada, com um objetivo prático, e que contribui para a construção de uma realidade comum a um conjunto social" (p. 22). A noção de RS refere-se a sistemas de interpretação, teorias não oficiais e espontâneas, a um saber prático que atua na relação do homem com o mundo, além de orientar e organizar a sua conduta e as comunicações sociais (Abric, 1998; Jodelet, 2001; Moscovici, 1978).

A pesquisa assumiu como pressuposto a idéia de que RS e práticas sociais estão em íntima relação (Abric, 2001; Rouquette, 1998; Wagner, 1993) e que as mudanças na assistência não passam apenas por questões técnicas, mas, principalmente, devem levar em conta as diferentes concepções acerca dela. Assim, o objetivo deste estudo foi investigar quais as RS que mulheres assistidas e profissionais de saúde têm sobre a assistência ao parto na maternidade e, além disso, comparar as representações dos dois grupos.

A pesquisa foi realizada em duas maternidades que apresentam modelos diferentes de assistência. Por questões éticas, as maternidades não foram identificadas e, neste estudo, foram denominadas de Maternidade A e Maternidade B.

A Maternidade A seguia uma forma de assistência cujas características a aproximavam mais do modelo medicalizado, no sentido de que preservava práticas hoje desaconselhadas pela OMS (1996), tais como, o uso rotineiro do enema (lavagem intestinal) e da tricotomia (corte dos pêlos pubianos). A Maternidade B, por sua vez, possuía uma filosofia de atenção explicitamente identificada com a proposta de humanização do parto, conforme se pôde observar em seu Manual de Rotinas Médicas. Esse documento estabelece condutas de assistência em conformidade com aquelas definidas pela OMS (1996) na implantação do parto humanizado nos serviços de saúde, entre elas a extinção de práticas como a episiotomia, o enema e a tricotomia na rotina de atendimento e ainda o estímulo à posição verticalizada durante o trabalho de parto.

Tinha-se por hipóteses: (a) o compartilhamento de RS entre os profissionais que trabalhavam em uma mesma maternidade, pelo fato de atuarem em instituições que adotavam modelos de assistência bem definidos; e (b) o compartilhamento de RS entre as mulheres assistidas em cada uma das maternidades investigadas pelo fato de elas terem sido submetidas à mesma forma de assistência.

Outro aspecto considerado em relação às mulheres foi o fato de as maternidades investigadas serem as únicas que prestavam assistência pelo Sistema Único de Saúde (SUS) na cidade em que se deu o estudo. Assim, havia a possibilidade de elas terem construído uma RS da assistência também a partir do contato com outras mulheres de sua rede de convivência que tiveram bebê nas instituições estudadas.

\section{Método}

Trata-se de um estudo comparativo entre dois grupos: 20 mulheres assistidas (referidas, nas citações, como MA) em duas maternidades públicas, pelo SUS, em uma cidade no Estado de Santa Catarina. Dez dessas mulheres foram atendidas na Maternidade A, e as outras 10, na Maternidade B. O segundo grupo foi constituído de 20 profissionais de saúde (referidos, nas citações, como PS) que atuavam diretamente na assistência ao parto nessas mesmas instituições. Dez dos profissionais trabalhavam na Maternidade A, e os outros 10, na Maternidade B.

Entre as mulheres entrevistadas, 10 tiveram seu filho por parto vaginal, enquanto 10 foram submetidas à cesariana. Em relação à idade, 10 tinham entre 18 e 24 anos, e as outras 10, entre 24 e 38 anos. Quanto ao estado civil, 15 eram casadas e cinco solteiras. No que concerne à escolaridade, 13 possuíam até o segundo grau completo 
e as outras sete tinham nível superior incompleto ou completo. Quinze mulheres contaram com acompanhante na hora do parto, enquanto as cinco restantes não. Com relação à participação em grupo para gestantes, oito mulheres participaram e 12 não.

Quanto aos profissionais de saúde, 15 eram médicos e cinco enfermeiras. É importante destacar que, na Maternidade $\mathrm{A}$, não foram entrevistadas enfermeiras, porque nessa instituição essas profissionais não são autorizadas a atender partos. Treze profissionais eram do sexo feminino e sete do sexo masculino. Em relação à idade, oito profissionais tinham entre 24 e 36 anos, enquanto 12 tinham entre 37 e 49 anos.

Para a coleta de dados, empregou-se a técnica de entrevista conduzida a partir de roteiro semi-estruturado. Utilizou-se um roteiro para cada grupo de participantes, cujos itens eram correspondentes para possibilitar, na análise, a sua comparação.

Os roteiros apresentavam uma parte composta de dados de identificação e questões sobre: motivos que os levaram a escolher determinada maternidade para trabalhar ou ter bebê, experiência de trabalhar ou ter bebê na maternidade escolhida, aspectos positivos e negativos que identificavam na assistência prestada ou recebida e a concepção do que seria uma assistência ideal. As mulheres assistidas foram entrevistadas em casa e os profissionais em seu local de trabalho. As entrevistas tiveram uma duração média de 40 minutos.

Para analisar os dados, utilizou-se uma análise lexicográfica e a técnica da classificação hierárquica descendente (CHD) de segmentos de texto originados da transcrição das entrevistas gravadas. Esse tipo de classificação considera a semelhança dos elementos que compõem cada segmento de texto para colocá-los em uma determinada classe. Para isso, utilizou-se o ALCESTE (Analyse Lexicale par Contexte d'un Ensemble de Segments de Texte), criado por Reinert (1998). Em quatro etapas, o programa organiza e classifica os segmentos de texto de acordo com a semelhança do vocabulário destes, oferecendo classes compostas de palavras típicas (que indicam elementos de RS) e segmentos de textos característicos dessas classes, os quais indicam a significação desses elementos (Camargo, 2005).

As variáveis relativas aos profissionais consideradas na análise foram as seguintes: idade, sexo, maternidade em que trabalhava, função exercida. Já para as mulheres, foram considerados: idade, estado civil, escolaridade, maternidade em que ocorreu o parto, tipo de parto (vaginal ou cesáreo), presença ou não do acompanhante no parto, participação ou não em grupos de gestantes durante a gravidez. Para a comparação entre os dois grupos, realizou-se uma meta-análise baseada na observação das semelhanças e diferenças encontradas nos resultados obtidos para cada grupo.

O material textual produzido por cada grupo de participantes foi dividido em dois corpora. No presente trabalho cada corpus foi formado pelo conjunto de respostas de cada grupo de participantes a um grupo de perguntas. Este artigo refere-se aos resultados relativos ao corpus "Assistência ao Parto". O segundo corpus, intitulado "Relação Profissional-Parturiente", tratava mais especificamente sobre como os sujeitos pesquisados representavam a relação que estabeleceram entre si na Maternidade. O presente estudo foi aprovado pelo Comitê de Ética em Pesquisa com Seres Humanos da Universidade Federal de Santa Catarina, sob o protocolo 075/04.

\section{Resultados e Discussão}

\section{AAssistência ao Parto Segundo os Profissionais de Saúde}

O corpus "Assistência ao Parto" produzido pelos profissionais de saúde era formado por 20 Unidades de Contexto Inicial (UCIs), correspondentes às 20 entrevistas realizadas. O corpus foi dividido em 1.244 Unidades de Contexto Elementar (UCEs), que continham 4.615 palavras diferentes, cuja ocorrência chegou a 53.742 vezes.

A Classificação Hierárquica Descendente (CHD) levou em conta 1.012 UCEs, ou seja, 81,3\% do total. A partir das UCEs consideradas, o corpus foi dividido em 4 classes (ver Figura 1). A primeira partição contrapôs a classe 3 às demais; a segunda classificou as classes 1 e 4 de um lado, e a classe 2 de outro.

A classe 2, denominada "A assistência humanizada", representou a maior parte das UCEs $(38,2 \%)$. Na Figura 1 pode-se observar as palavras significativamente associadas a ela.

Havia dois critérios para essa apresentação: a freqüência de ocorrência deveria ser maior que uma vez e meia o valor da média, ou seja, 18, e o Qui-quadrado de associação da palavra à classe deveria ser maior que 3,84, já que o grau de liberdade era igual a 1 .

A classe 2 foi produzida predominantemente por profissionais da Maternidade B, pela categoria das enfermeiras obstetras e por profissionais com idade entre 37 e 49 anos. Os elementos centrais dessa classe (ver Figura 1) apontaram para uma forma de pensar a assistência identificada com o ideário da humanização do parto.

De acordo com essa concepção, grande importância foi dada à presença do acompanhante e também à participação da enfermeira obstetra no processo de parto, conforme se pode observar no seguinte segmento de texto: "A gente sempre procura fazer um trabalho humani-zado, e dentro da humanização, uma das coisas que eu acho extremamente importante, que eu vejo como um aspecto positivo da assistência que é prestada aqui é permitir a presença de um acompanhante (PS1- Enfermeira, Maternidade B)".

Para esses profissionais, a atuação das enfermeiras estaria ligada a uma postura profissional mais relacionada ao cuidado e menos relacionada à intervenção no nascimento, característica que ajudaria a compor a assistência humanizada. Por outro lado, observou-se que a identificação com a filosofia de atendimento da Maternidade $\mathrm{B}$ não foi comum a todos os profissionais. Estes 


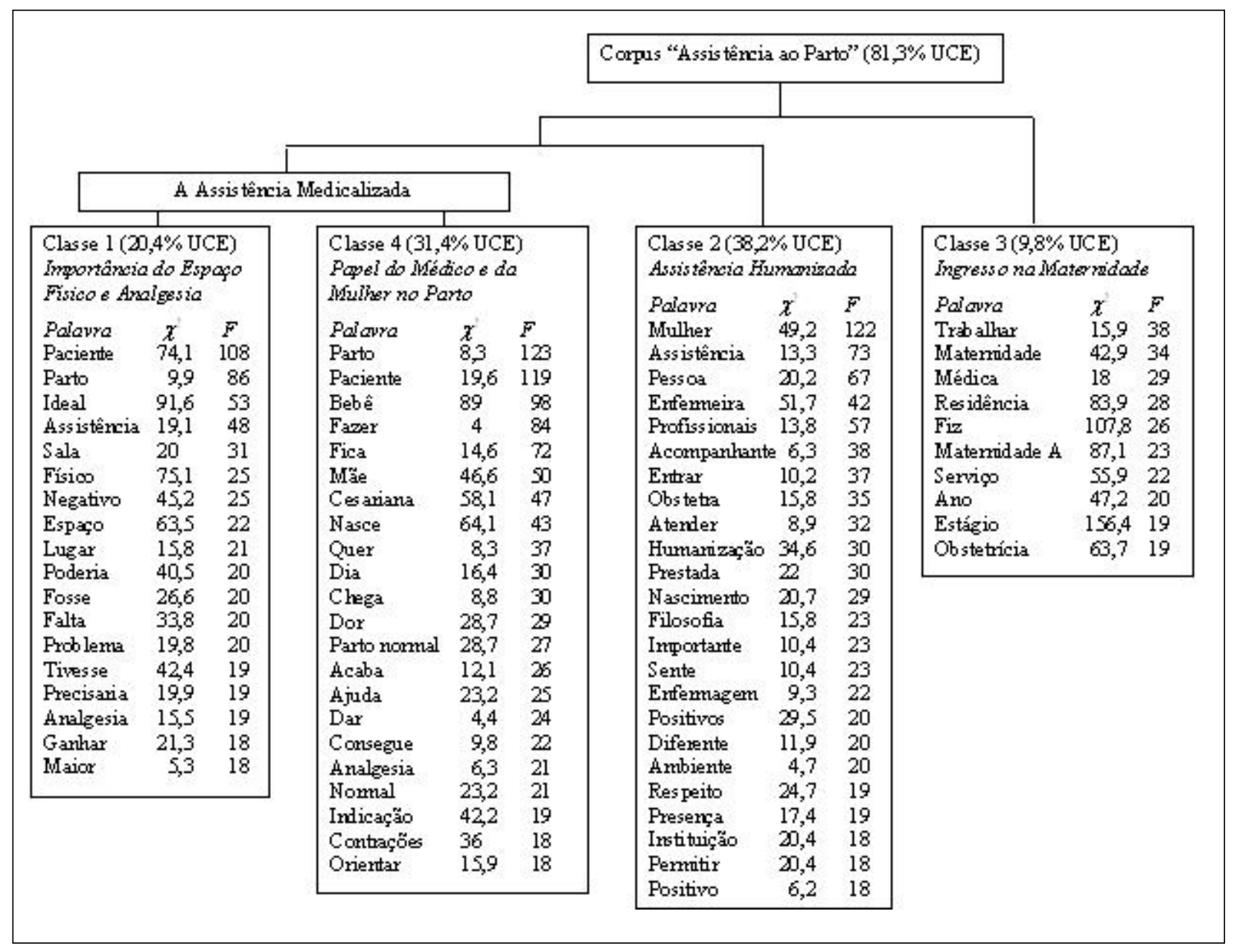

Figura 1. Classificação Hierárquica Descendente das respostas do grupo de profissionais relativas ao corpus Assistência ao Parto.

reconheceram que havia divergências importantes na maneira de pensar a assistência naquela instituição, o que levava a uma heterogeneidade de condutas e gerava atritos dentro da equipe.

Constatou-se ainda que, ao se identificarem com a proposta de humanização, os profissionais privilegiaram alguns sentidos dessa abordagem, conforme as definições encontradas por Diniz (2005). Um desses sentidos é aquele que defende um redimensionamento dos papéis e poderes na assistência, o que inclui o deslocamento da função principal, ou pelo menos exclusiva, no parto normal, do cirurgião obstetra para a enfermeira obstetriz. Outro sentido atribuído à humanização pelos profissionais da Maternidade $\mathrm{B}$ é o que confere legitimidade à participação da parturiente nas decisões.

A classe 4, denominada "O Papel do Médico e da Mulher no parto", em conjunto com a classe 1, fazia parte da ramificação denominada "A assistência medicalizada" (ver Figura 1). Ambas as classes foram produzidas predominantemente por profissionais que trabalhavam na Maternidade A, exerciam a função de médico e tinham idade entre 24 e 36 anos.

A classe 4 foi composta por 318 UCEs, o que equivale a $31,4 \%$ do total. Na Figura 1, pode-se observar as pala- vras mais significativamente associadas a ela. A análise dessa classe permitiu constatar que seu conteúdo trata de como os profissionais que a produziram entendiam o seu papel e o da mulher no momento do parto. De acordo com essa forma de pensar, a função principal no momento do parto foi atribuída ao médico, enquanto que à mulher foi atribuído um papel passivo.

Nesse sentido, encontraram-se de forma marcante nesse grupo noções que apontavam para a idéia de que cabia ao médico "fazer" coisas durante o processo de parto, como o próprio parto e uma série de práticas de assistência, como, por exemplo, a episiotomia (incisão cirúrgica da vulva), a prescrição do enema e da tricotomia. Vale ressaltar que o verbo "fazer" foi bastante recorrente (84 vezes) nessa classe. Em alguns momentos, os próprios profissionais reconheceram realizar algumas dessas práticas, como por exemplo, a episiotomia, por sentimentos como medo e insegurança, e não por uma indica-ção técnica sustentada pela ciência, conforme demonstra o seguinte segmento de texto: "No começo, até por insegurança, tu acabas fazendo [a episiotomia], por ficar nervosa de ver a cabeça do bebê que vem e vai e não nasce, daí tu dás a anestesia e faz, porque ajuda um pouco" (PS2 - Médica, Maternidade A). 
Outro papel atribuído à categoria foi o de orientar a parturiente. Na visão desses profissionais, o papel da mulher parecia se restringir a fazer força e ajudá-los a fazer o parto, e caberia a eles orientá-la sobre o momento certo de fazer força. Assim, o papel de orientar, muitas vezes, estava relacionado com dizer à mulher o que $\mathrm{e}$ como fazer durante o processo de parto.

A classe 1, denominada "Importância do Espaço Físico e da Analgesia" foi composta por 207 UCEs, o que representou $20,4 \%$ do total. Os elementos centrais dessa classe (ver Figura 1) revelaram que seu conteúdo estava relacionado principalmente a como os profissionais que a produziram (principalmente médicos da Maternidade A com idade entre 24 e 36 anos) pensavam que seria uma assistência ideal, como eles percebiam a assistência prestada na maternidade em que trabalhavam e, ainda, os seus aspectos negativos.

$\mathrm{Na}$ opinião desses profissionais, o espaço físico tinha um papel determinante na maneira de ver a assistência prestada e de pensar como seria uma assistência ideal. As palavras "espaço", "físico" e "pequeno" apresentaram relação entre si, associação recorrente nessa classe. O espaço físico reduzido para o tamanho da demanda atendida pela Maternidade A foi um aspecto negativo da assistência bastante citado por esses profissionais. Na sua visão, uma área física organizada de modo a proporcionar privacidade e comodidade para as parturientes seria uma característica importante de uma assistência ideal.

Outra correlação percebida nessa classe foi entre as palavras "falta" e "analgesia". A impossibilidade de oferecer parto com analgesia peridural para todas as usuárias do SUS foi identificada de forma significativa por esses profissionais como um aspecto negativo da assistência prestada. Além disso, a ampla oferta desse recurso foi destacada como uma característica importante da assistência ideal.

Assim, os profissionais que trabalhavam na Maternidade A, por sua vez, pareciam se identificar mais com o modelo hegemônico de atenção ao parto, ou seja, o "modelo tecnocrático", conforme o definem Davis-Floyd e St. John (2004). Um aspecto desse modelo encontrado estava relacionado com um de seus princípios, qual seja, o que delega toda autoridade ao médico. O médico é o perito, é ele quem "faz" o parto, enquanto a paciente fica submetida à sua vontade. Desta forma, entre esses profissionais, parecia predominar um elemento de RS segundo o qual o parto é visto não como uma atividade em que a mulher tem o papel principal, mas como um serviço a ser prestado pela medicina.

Outra característica do modelo tecnocrático encontrada foi o princípio de "curar de fora para dentro". A adoção desse princípio tem por conseqüência o emprego de táticas agressivas na assistência, a exemplo do uso de práticas intervencionistas como o enema e a tricotomia em todas as mulheres.

Contudo, embora a Maternidade A parecesse estar mais identificada com o modelo hegemônico de assistência, observou-se também, no relato de seus profissionais, algumas noções que apontaram para a presença de aspectos humanizadores na maneira de compreendê-la. Um exemplo disso é a preocupação com a privacidade e a comodidade das pacientes, conforme apontado anteriormente.

A classe 3 não representou grande relevância para esta análise, uma vez que seu conteúdo girava em torno de uma questão que, no roteiro de perguntas, tinha como função principal apenas introduzir o assunto objeto da pesquisa. Por esse motivo, a referida classe não será analisada no presente estudo.

Desta forma, observou-se que houve compartilhamento de RS entre profissionais que trabalhavam numa mesma maternidade, apesar de ter havido algumas divergências na maneira de pensar a assistência entre os profissionais de cada um dos grupos investigados.

\section{A Assistência ao Parto Segundo as Mulheres Assistidas}

O corpus "Assistência ao Parto" produzido pelo grupo das mulheres assistidas era composto por 20 UCIs, correspondentes às 20 entrevistas realizadas. O corpus foi dividido em 806 UCEs, contendo 2.881 palavras diferentes que ocorreram 35.624 vezes.

A CHD levou em conta 661 UCEs, ou seja, $82 \%$ do total. A partir das UCEs consideradas, o corpus foi dividido em 4 classes (ver Figura 2). Assim, houve uma primeira divisão em dois subcorpora, aquele que originou as classes 1 e 3 (A Assistência) e o que originou as classes 2 e 4 (O Parto).

Desta forma, observou-se, de um lado, uma relação de proximidade entre as classes agrupadas na ramificação denominada "A Assistência" e, por outro, uma relação de diferenciação destas em relação àquelas agrupadas na ramificação denominada "O Parto". A análise dessas ramificações revelou que a primeira tratava mais especificamente da assistência recebida, e a segunda estava mais relacionada à experiência do parto pelas mulheres.

É importante assinalar que, com relação a esse grupo de participantes, a análise realizada pelo ALCESTE demonstrou não haver uma contribuição significativa das variáveis investigadas para a compreensão das suas RS sobre o tema em questão. Vale ressaltar também que pesquisas correlatas têm apontado pouca ou nenhuma relação entre fatores demográficos como idade, escolaridade e nível socioeconômico e a maneira de perceber a assistência ao parto (Green \& Baston, 2003; Hodnett, 2002; Waldenström, 2004; Waldenström, Hildingsson, Rubertsson, \& Radestad, 2004).

A classe 4, denominada "Vivência do Processo de Parto" representou a maior parte das UCE $(53,1 \%)$, e a Figura 2 apresenta as palavras significativamente associadas a ela. A análise dessa classe revelou sua relação com alguns acontecimentos que cercaram o nascimento do bebê, destacando-se a forma como as parturientes experienciaram o transcorrer do tempo durante todo o processo de parto e de permanência na maternidade, 
assim como passar por essa experiência assistindo a outras mulheres que viviam o mesmo processo. $\mathrm{O}$ tempo de permanência na maternidade foi percebido pelas mulheres como um período demorado, conforme se pode observar no seguinte segmento de texto:
"Se eu tivesse ficado ali o dia inteiro, com aquela funcionária falando que é assim mesmo, se a médica não tivesse vindo, se o meu marido não tivesse chamado, eu ficaria ali muito mais tempo" (MA1, Maternidade A).

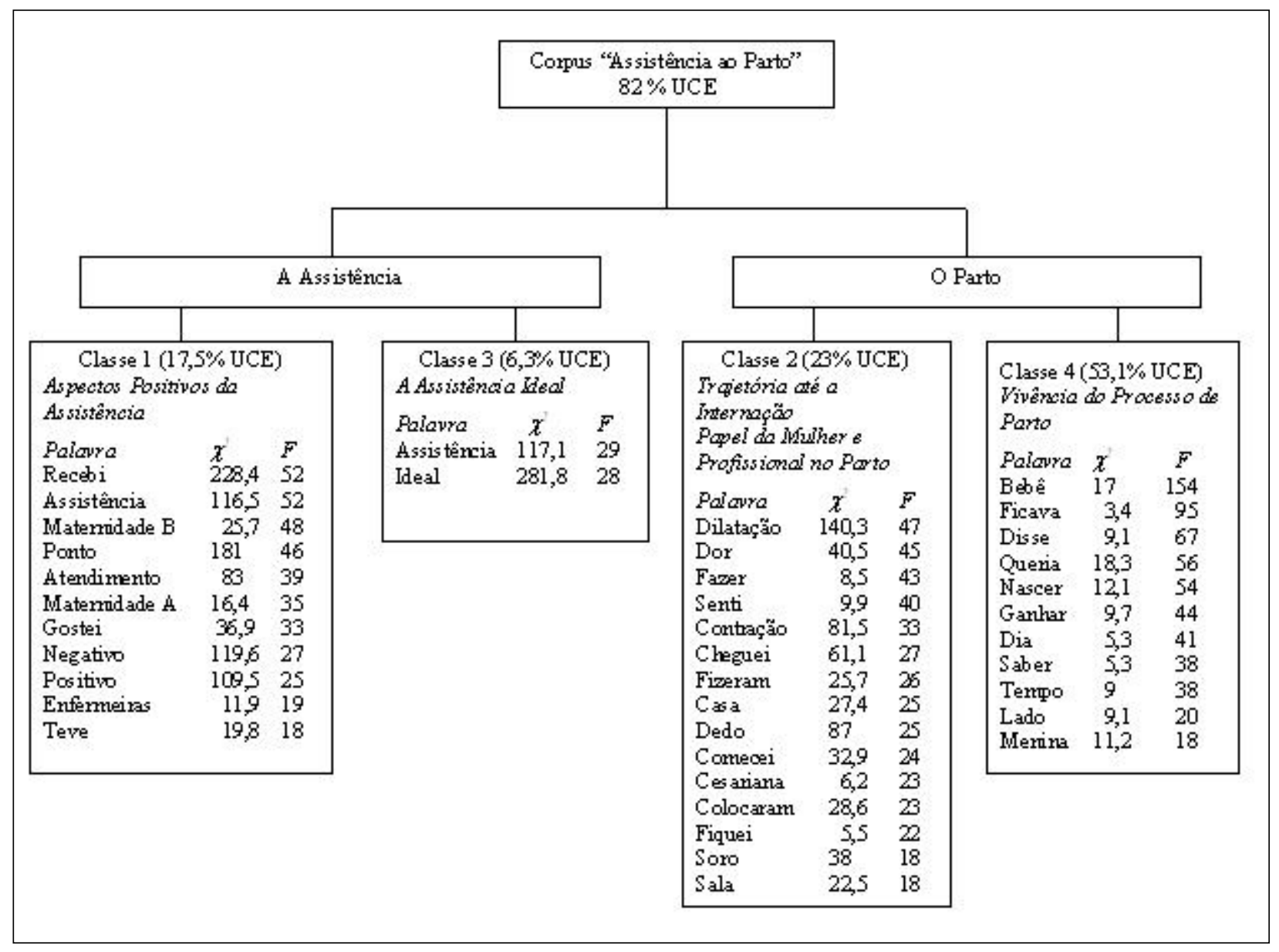

Figura 2. Classificação Hierárquica Descendente das respostas do grupo de mulheres assistidas relativas ao corpus Assistência ao Parto.

Desta forma, tanto o nascimento do bebê quanto o retorno à sua casa eram aguardados com ansiedade. Contribuiu para a produção desse aspecto das RS principalmente o grupo das mulheres atendidas na Maternidade $\mathrm{A}$, que não tiveram acompanhante e com escolaridade até o ensino médio completo.

As palavras "menina" e "lado" foram recorrentes nessa classe e estavam associadas. Tal associação revelou que a experiência de presenciar o processo de parto de outras mulheres internadas parecia se constituir em uma vivência marcante para as mulheres e exercer uma interferência geralmente negativa na maneira como elas experimentavam o seu próprio processo de parto.

Deduz-se que essa interferência ocorreu porque a maneira como o espaço físico estava estruturado nas maternidades analisadas permitia que uma mulher presenciasse o trabalho de parto de outras mulheres. Isso, por sua vez, acabava levando-as a fazer comparações entre o que acontecia com elas e o que acontecia com as outras mulheres, o que contribuía para aumentar a sensação de medo e gerar expectativas, que muitas vezes, não se aplicavam à sua situação. Contribuíram para a produção desse aspecto das RS principalmente as mulheres com escolaridade superior ao ensino médio completo, que tiveram acompanhante no parto e eram casadas.

A classe 2, denominada "A Trajetória até a Internação, o Papel da Mulher e do Profissional no Parto" foi composta por 152 UCEs, o que representou $23 \%$ do total. A Figura 2 apresenta as palavras significativamente associadas a ela. Contribuíram para sua formação as UCE produzidas principalmente por mulheres que não tiveram acompanhante no parto, com escolaridade até o ensino médio completo e que foram atendidas na Maternidade $\mathrm{A}$. A análise dessa classe revelou a trajetória percorrida pelas mulheres desde a hora em que perceberam, em casa, os primeiros sinais do trabalho de parto até o 
momento do parto na maternidade, e também a maneira como elas perceberam o seu papel e o dos profissionais de saúde no processo.

Os resultados encontrados sugeriram que a assistência prestada pelas instituições investigadas parecia se organizar de modo a proceder à internação das parturientes em trabalho de parto com evolução normal, em um determinado momento previamente determinado pela equipe de saúde. Porém, esse critério de internação nem sempre parecia estar claro para as mulheres. Estas, ao contrário, demonstraram acreditar que, para serem admitidas na maternidade, era suficiente estar sentindo dores e contrações. Esse fato, por sua vez, fez com que elas fossem orientadas pelos profissionais a retornar para casa, às vezes em mais de uma ocasião, o que, em muitos momentos, acarretou uma experiência geradora de estresse, conforme se observa no seguinte trecho:

"Eu ia para a maternidade e voltava. Quando eu chegava lá, eles me mandavam caminhar, mas nada adiantava e eu voltava para casa" (MA2 - Maternidade A).

A análise dessa classe revela também que as mulheres se perceberam desempenhando um papel mais passivo durante o processo, enquanto atribuíram aos profissionais um papel mais ativo, mesmo naquelas situações em que a função principal caberia a elas, como o próprio ato de parir. Observou-se, ainda, que a maioria das mulheres entrevistadas se referiu espontaneamente a várias práticas às quais foram submetidas na maternidade, onde raras foram as vezes em que houve um questionamento sobre a necessidade ou não da realização desses procedimentos.

Os resultados apontam para um elemento de RS de que o conhecimento dos profissionais de saúde é superior ao delas que vivenciam a experiência de parir. Por outro lado, revelam também uma subordinação ao poder médico que historicamente caracteriza a assistência ao parto em nossa sociedade, conforme demonstram Melo (1983) e Spink (2003). Outros estudos também têm observado a submissão da mulher às rotinas hospitalares (Campero et al., 1998; Soares \& Silva, 2001). Um dado que chamou a atenção na análise dessa classe foi que a maior parte das mulheres que se percebeu desempenhando o papel mais passivo no parto tenha sido atendida na Maternidade A, instituição que estava mais identificada com o modelo tecnocrático de atenção.

A segunda ramificação tratava da assistência propriamente dita. A classe 1, denominada "Aspectos Positivos da Assistência" foi composta por 116 UCEs, o que representou $17,5 \%$ do total. Observou-se que essa classe teve uma relativa importância para as mulheres solteiras, uma vez que $31,8 \%$ das UCE produzidas por elas foram classificadas aqui. A Figura 2 apresenta as palavras/ noções mais importantes associadas à classe 1, e sua análise revelou que tais palavras estão relacionadas a como as mulheres perceberam a assistência recebida nas Maternidades A e B, sendo que foi dada ênfase aos seus aspectos positivos.
Outras pesquisas correlatas, principalmente aquelas que investigam a satisfação da mulher no parto, têm encontrado em seus resultados altos níveis de satisfação (Campero et al., 1998; Domingues et al., 2004; Maternity Center Association, 2004; Motta, 2003; Teijlingen, Hundley, Rennie, Graham, \& Fitzmaurice, 2003; Tornquist, 2004; Waldenström et al., 2004). Os estudos indicam que há uma tendência de as mulheres avaliarem bem seus cuidadores, mesmo quando apontam descontentamento quanto à forma como foram tratadas.

Muitos trabalhos também têm apontado para uma tendência, percebida em pesquisas sobre satisfação realizadas muito próximas ao parto, em apresentar resultados mascarados pelo alívio decorrente do fato de o parto ter tido um desfecho feliz (Domingues et al., 2004; Hodnett, 2002; Teijlingen et al, 2003; Waldenström et al., 2004). Portanto, é necessário considerar a possível interferência desses fatores nos resultados encontrados. Entre os aspectos positivos mais citados, a atenção recebida da equipe de saúde foi o mais recorrente, conforme se pode observar no seguinte trecho: "Quanto aos pontos que eu achei mais positivos na assistência que eu recebi na Maternidade A, eu não sei, eu acho que foi o atendimento mesmo, as pessoas foram bem atenciosas comigo" (MA2 - Maternidade A).

Os aspectos relacionados com a atenção foram: explicações fornecidas em linguagem acessível, freqüência do cuidado, tempo dispensado pelos profissionais para ficar ao seu lado, prontidão no atendimento, ajuda da equipe de enfermagem para amamentar, acompanhamento intensivo no pós-operatório, entre outros. Identificou-se também que as profissionais de enfermagem desempenharam um papel importante na maneira como as mulheres perceberam a assistência recebida, principalmente na proporção em que forneceram explicações sobre o que estava acontecendo durante a internação.

Quanto aos aspectos negativos da assistência, embora tenham sido menos citados, o que teve maior ocorrência foi o tipo de atendimento prestado por alguns profissionais. Este foi percebido pelas mulheres como grosseiro, impaciente, desumano, pouco atencioso, entre outras características apontadas.

A classe 3, denominada "A Assistência Ideal”, foi composta por 42 UCEs, representando apenas $6,3 \%$ do total, e não foi relacionada de maneira importante a variável alguma. As palavras significativamente associadas a essa classe (ver Figura 2) estavam relacionadas aos aspectos que as mulheres acreditavam tornar uma assistência ideal, quais sejam: ter uma boa relação com os profissionais de saúde e a possibilidade de poder contar sempre com a presença do acompanhante durante o parto.

Portanto, esses dados parecem apontar para um elemento de RS entre as mulheres assistidas, segundo o qual, uma boa assistência seria aquela em que os profissionais fossem atenciosos, sendo a atenção identificada com os aspectos definidos anteriormente. Uma assistência ruim, por outro lado, seria aquela em que os profissionais fos- 
sem pouco atenciosos com as parturientes e as tratassem de forma desrespeitosa.

Constatou-se assim que houve compartilhamento de RS entre o grupo das mulheres assistidas e ainda que não houve diferenças significativas na maneira de ver a assistência entre o grupo de mulheres atendidas na Maternidade A e aquele atendido na Maternidade B.

\section{Considerações Finais}

Uma comparação entre o grupo das mulheres e o dos profissionais de saúde permitiu observar alguns pontos de convergência e outros de divergência na RS da assistência. Os profissionais, de maneira geral, destacaram como aspectos importantes da assistência: a presença do acompanhante, a preocupação com a sua humanização, a participação da enfermeira obstetra e o espaço físico. As mulheres assistidas, por sua vez, destacaram de maneira importante a atenção recebida dos profissionais em ambas as maternidades.

Portanto, cada um dos grupos enfatizou aspectos diferentes ao falar da assistência. Contudo, partindo do pressuposto de que dispensar atenção é um aspecto que compõe a proposta do MHPN, parece haver uma correspondência entre a maneira como os profissionais da Maternidade B e as mulheres percebem a assistência, ou seja, ambos os grupos valorizam os seus aspectos humanizadores, embora cada um deles tenha enfatizado pontos diferentes ao abordar essa questão. Assim, enquanto os profissionais destacaram aspectos da humanização como a presença do acompanhante, a participação ativa da mulher no nascimento de seu filho e uma postura não intervencionista no parto, as mulheres ressaltaram a atenção dispensada pela equipe de saúde.

Outra semelhança entre os dois grupos na maneira de ver a assistência está relacionada à participação da equipe de enfermagem no parto. Os profissionais, sobretudo os que trabalhavam na Maternidade B, e as enfermeiras obstetras perceberam a participação dessa profissional como um elemento muito importante da assistência. As mulheres, por sua vez, fizeram referências constantes às profissionais identificadas por elas como enfermeiras. Essas referências parecem indicar que essas profissionais foram as que tiveram mais contato com as mulheres durante sua permanência na maternidade e, embora tenham sido citadas algumas dificuldades na relação com elas, os aspectos positivos da convivência foram os mais lembrados. Assim, percebe-se uma convergência na maneira de ver a assistência nos dois grupos, ou seja, ambos consideraram que a participação da enfermagem na assistência desempenha um papel importante.

Quanto à presença do acompanhante durante o processo de parto, observou-se que, embora ela tenha sido referida pelas mulheres e pelos profissionais como um aspecto importante da assistência, o grupo dos profissionais foi o que maior valor atribuiu a esse aspecto.
Com relação ao espaço físico, observou-se sua relevância para os dois grupos, embora, novamente, o dos profissionais tenha sido o que maior importância atribuiu a esse aspecto. No que concerne à concepção de como deveria ser uma assistência ideal, o aspecto mais citado pelos profissionais foi disponibilizar o recurso da analgesia a todas as parturientes sem contra-indicação para o seu uso. Já as mulheres mencionaram, como principal característica de uma assistência ideal, ter uma boa relação com os profissionais de saúde e ainda a presença do acompanhante. Dessa forma, percebeu-se haver divergências consideráveis entre os dois grupos quanto a essa questão.

Quanto aos aspectos negativos, observaram-se diferenças marcantes entre os dois grupos, na medida em que o grupo dos profissionais identificou mais aspectos negativos do que o grupo das mulheres ao falarem sobre a assistência. $\mathrm{O}$ aspecto negativo mais citado pelos profissionais foi a impossibilidade de oferecer analgesia para todas as mulheres sem contra-indicações para o seu uso. As mulheres, por sua vez, em momento algum mencionaram a ausência da analgesia como um aspecto negativo da assistência e, embora tenham feito referências à experiência incômoda de sentir dor, demonstraram assumi-la como uma dimensão natural do processo de parir. Por outro lado, o aspecto negativo mais citado por esse grupo foi o atendimento de alguns profissionais de saúde, conforme citado anteriormente.

Quanto à maneira de pensar os papéis dos profissionais e das mulheres no momento do parto, houve uma semelhança entre os dois grupos, ou seja, o papel desempenhado pelo médico foi percebido como o mais importante para que o processo se desenvolva sem complicações.

Por último, com relação à maneira de ver o papel da dor no parto, observou-se uma diferença marcante entre os dois grupos. Enquanto os profissionais pareceram vê-la como um mal a ser combatido, principalmente com recursos farmacológicos, as mulheres, apesar de terem, em muitos momentos, manifestado o desejo de que a dor cessasse logo, pareceram não valorizar esse aspecto.

Portanto, em uma comparação entre o grupo das mulheres assistidas e o dos profissionais, um dos resultados encontrados e que mais chamou a atenção foi o fato de que, apesar de haver diferenças importantes entre as RS dos dois grupos de profissionais analisados e de essas diferenças também serem percebidas nas práticas assistenciais de cada uma das instituições representadas por esses grupos, elas não exerceram uma influência determinante na maneira como as mulheres representaram ou avaliaram a assistência recebida.

$\mathrm{O}$ que os resultados indicam é que o que exerceu uma influência importante na maneira como as mulheres percebiam a assistência foi a qualidade da relação estabelecida com os profissionais de saúde. Ou seja, a assistência pareceu ser percebida positivamente na proporção em que 
as mulheres sentiram receber "atenção" dos profissionais. Esse resultado vai ao encontro de outros estudos na área, que têm demonstrado a forte influência que a qualidade da relação com os cuidadores exerce sobre a satisfação das mulheres no parto (Domingues et al., 2004; Fowles, 1998; Green \& Baston 2003; Hodnett, 2002; Motta, 2003; O. M. B. Santos \& Silbert, 2001; Waldenström, 2004; Waldenström et al., 2004).

Levando em consideração a grande vulnerabilidade psicológica da mulher no momento do parto, conforme demonstra a literatura (Langer, 1986; Maldonado, 2000; Rosfelter, 1994; Videla, 1997) e o quanto o contexto assistencial pode interferir em sua experiência, avalia-se ser fundamental que a qualidade da relação entre equipe e parturiente seja foco de atenção nos esforços para melhorar a assistência prestada nas maternidades e outras instituições que dispensam cuidados na área em questão. Assim, em vez do investimento em gastos públicos onerosos com ações como disponibilizar o recurso da analgesia para todas as parturientes, como defendem os médicos da Maternidade A, considera-se prioritário o investimento no aprimoramento de habilidades relacionais dos profissionais de saúde envolvidos na assistência.

\section{Referências}

Abric, J. C. (1998). Abordagem estrutural das representações sociais. In A. S. P. Moreira \& D. C. Oliveira (Eds.), Estudos interdisciplinares de representação social (pp. 27-38). Goiânia, GO: AB.

Abric, J. C. (2001). O estudo experimental das representações sociais. In D. Jodelet (Ed.), As representações sociais (pp. 155-171). Rio de Janeiro, RJ: Editora da Universidade Estadual do Rio de Janeiro.

Alves, M. T. S. S. B. (2002). O parto na maternidade: Qualidade da assistência, o dia-a-dia do trabalho e o olhar das mulheres. In R. M. Barbosa, E. M. L. Aquino, M. L. H. Born, \& E. Berquó (Eds.), Interfaces-gênero, sexualidade e saúde reprodutiva (pp. 279-305). Campinas, SP: Editora da Universidade Estadual de Campinas.

Camargo, B. V. (2005) Alceste: Um programa informático de análise quantitativa de dados textuais. In A. S. P.Moreira, B. V.Camargo, J. C. Jesuíno \& S. M. Nóbrega (Eds.), Perspectivas teórico-metodológicas em representações sociais (pp. 511-539). João Pessoa, PB: Editora Universitária da Universidade Federal da Paraíba.

Campero, L., Garcia, C., Diaz, C., Ortiz, O., Reynoso, S., \& Langer, A. (1998). Alone, I wouldn't have known what to do: A qualitative study on social support during labor and delivery. Mexico Social Science \& Medicine, 47(3), 395403.

Caron, O. P. F., \& Silva, I. A. (2002). Parturiente e equipe obstétrica: A difícil arte da comunicação. Revista Latino Americana de Enfermagem, 10(4), 485-492.

Davis-Floyd, R., \& St. John, G. (2004). Del medico al sanador. Buenos Aires, Argentina: Creavida.

Diniz, C. S. G. (2001). Entre a técnica e os direitos humanos: Possibilidades e limites da humanização da assistência ao parto. Tese de Doutorado não-publicada, Universidade de São Paulo, SP.
Diniz, C. S. G. (2005). Humanização da assistência ao parto no Brasil: Os muitos sentidos de um movimento. Ciência e Saúde Coletiva, 10(3), 627-637.

Domingues, R. M. S. M., Santos, E. M., \& Leal, M. C. (2004). Aspectos da satisfação das mulheres com a assistência ao parto: Contribuição para o debate. Cadernos de Saúde Pública, 20(Supl. 1), S52-S62.

Fernandes, B. M. (2000). Representações femininas do parto normal e da cesárea. In E. R. Brandão (Ed.), Saúde, direitos reprodutivos e cidadania (pp. 27-54). Juiz de Fora, MG: Editora da Universidade Federal de Juiz de Fora.

Fowles, E. R. (1998). Labor concerns of women two months after delivery. Birth, 25(4), 235-240.

Green, J. M., \& Baston, H. A. (2003). Feeling in control during labor: Concepts, correlates, and consequences. Birth, 30(4), 235-247.

Hodnett, E. D. (2002). Pain and women's satisfaction with the experience of childbirth: A systematic review. American Journal of Obstetrics and Gynecology, 186(Suppl. 5), S160S172.

Hotimsky, S. N., Rattner, D., Venancio, S. I, Bógus, C. M., \& Miranda, M. M. (2002). O parto como eu vejo... ou o parto como eu desejo? Expectativas de gestantes, usuárias do SUS, acerca do parto e da assistência obstétrica. Cadernos de Saúde Pública, 18(5), 1303-1311.

Jodelet, D. (2001). Representações sociais: Um domínio em expansão. In D. Jodelet (Ed.), As representações sociais (pp. 17-41). Rio de Janeiro, RJ: Editora da Universidade Estadual do Rio de Janeiro.

Langer, M. (1986). Maternidade e sexo. Porto Alegre, RS: Artes Médicas.

Laurenti, R., Jorge, M. H. P. M., \& Gotlieb, S. L. D. (2004). A mortalidade materna nas capitais brasileiras: Algumas características e estimativas de um fator de ajuste. Revista Brasileira de Epidemiologia, 7(4), 449-460.

Maldonado, M. T. (2000). Psicologia da gravidez, parto $e$ puerpério (15. ed.). São Paulo, SP: Saraiva.

Maternity Center Association. (2004). Recommendations from listening to mothers: The first national U. S. survey of women's childbearing experiences. Birth, 31(1), 61-65.

Melo, V. H. (1983). Evolução histórica da obstetrícia: A marginalidade social das parteiras e da mulher. Dissertação de Mestrado não-publicada, Universidade Federal de Minas Gerais, Belo Horizonte, MG.

Ministério da Saúde. (2006). Data/Sus. Retrieved June 30, 2007, from http://tabnet.datasus.gov.br/cgi/tabcgi.exe ?idb2006/f08.def

Moscovici, S. (1978). A representação social da psicanálise. Rio de Janeiro, RJ: Zahar.

Motta, C. C. L. (2003). Quem acolhe esta mulher? Caracterização do apoio emocional à parturiente. Dissertação de Mestrado não-publicada, Universidade Federal de Santa Catarina, Florianópolis, SC.

Organização Mundial da Saúde. (1985). Tecnologia apropriada para o nascimento e parto. Lancet, 24, 436-437.

Organização Mundial da Saúde. (1996). Maternidade segura, assistência ao parto normal: Um guia prático. Genebra, Suíça: Saúde Materna e Neonatal.

Rede Feminista de Saúde. (2001). Dossiê mortalidade materna. Retrieved November 02, 2003, from http:// www.redesaude.org.br/Homepage/Dossi\%EAs/Dossi\% EA\%20Mortalidade\%20Materna.pdf 
Reinert, M. (1998). ALCESTE, une méthodologie d'analyse des données textuelles et une application. Bulletin de Méthodologie Sociologique, 28, 24-54.

Rosfelter, P. (1994). El nascimento de uma madre: bebe blues. Buenos Aires, Argentina: Nueva Visión.

Rouquette, M. L. (1998). Representações e práticas sociais: Alguns elementos teóricos. In A. S. P. Moreira, \& D. C. Oliveira (Eds.), Estudos interdisciplinares de representação social (pp. 39-46). Goiânia, GO: AB.

Santos, M. L. (2002). Humanização da assistência ao parto e nascimento: Um modelo teórico. Dissertação de Mestrado não-publicada, Universidade Federal de Santa Catarina, Florianópolis, SC.

Santos, O. M. B., \& Sibert, E. R. C. (2001). The humanization of birth experience at the University of Santa Catarina Maternity Hospital. Journal of Gynecology \& Obstetrics, 75, 873-879.

Soares, A. V. N., \& Silva, I. A. (2001). Hospitalização: Do abandono ao acolhimento - Representações de puérperas sobre internação em uma maternidade [Resumo]. In C. M. N. Schulze, \& B. V. Camargo (Eds.), II Jornada Internacional sobre Representações Sociais: Questões metodológicas (pp. 173). Florianópolis, SC: Editora da Universidade Federal de Santa Catarina.

Spink, M. J. P. (2003). As origens históricas da obstetrícia modera. In M. J. P. Spink, Psicologia social e saúde (pp. 169-193). Petrópolis, RJ: Vozes.

Teijlingen, E. R., Hundley, V., Rennie, A. M., Graham, W., \& Fitzmaurice, A. (2003). Maternity satisfaction studies and their limitations: What is, must be best. Birth, 30(2), 75-80.

Tornquist, C. S. (2004). Parto e poder: O movimento pela humanização do parto no Brasil. Tese de Doutorado nãopublicada, Universidade Federal de Santa Catarina, Florianópolis, SC.

Videla, M. (1997). Maternidade: mito e realidade. Buenos Aires, Argentina: Nueva Vision.

Wagner, W. (1993). Can representations explain behaviour? A discussion of social representations as rational sistems. Papers on Social Representations, 2(3), 236-249.

Waldenström, U. (2004). Why do some women change their opinion about childbirth over time? Birth, 31(2), 102-107.

Waldenström, U., Hildingsson, I., Rubertsson, C., \& Radestad, I. (2004). A negative birth experience: Prevalence and risk factors in a national sample. Birth, 31(1), 17-27. 